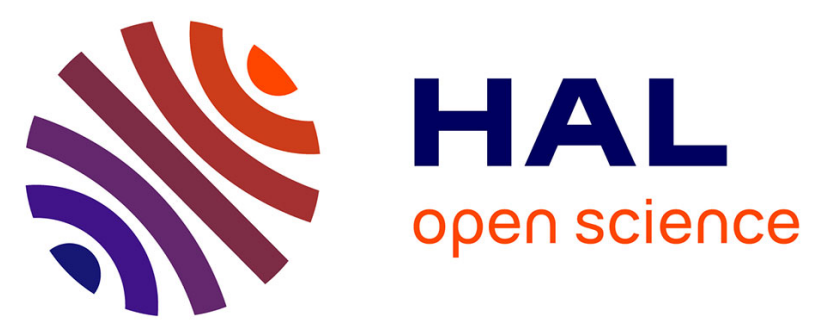

\title{
Cold Model Study of a 1.5 MW th Circulating Turbulent Fluidized Bed Fuel Reactor in Chemical Looping Combustion
}

$\mathrm{Hu}$ Chen, Zhenshan Li, Xinglei Liu, Weicheng Li, Ningsheng Cai, Sina Tebianian, Stéphane Bertholin, Mahdi Yazdanpanah, Aoling Zhang

\section{To cite this version:}

$\mathrm{Hu}$ Chen, Zhenshan Li, Xinglei Liu, Weicheng Li, Ningsheng Cai, et al.. Cold Model Study of a 1.5 MW th Circulating Turbulent Fluidized Bed Fuel Reactor in Chemical Looping Combustion. Energy \& Fuels, 2020, 34 (7), pp.8575-8586. 10.1021/acs.energyfuels.0c00971 . hal-02957871

\section{HAL Id: hal-02957871 \\ https://hal-ifp.archives-ouvertes.fr/hal-02957871}

Submitted on 5 Oct 2020

HAL is a multi-disciplinary open access archive for the deposit and dissemination of scientific research documents, whether they are published or not. The documents may come from teaching and research institutions in France or abroad, or from public or private research centers.
L'archive ouverte pluridisciplinaire HAL, est destinée au dépôt et à la diffusion de documents scientifiques de niveau recherche, publiés ou non, émanant des établissements d'enseignement et de recherche français ou étrangers, des laboratoires publics ou privés. 


\title{
Cold Model Study of a $1.5 \mathrm{MW}_{\text {th }}$ Circulating Turbulent Fluidized Bed Fuel Reactor in Chemical Looping Combustion
}

Hu Chen ${ }^{1}$, Zhenshan $\mathrm{Li}^{1 *}$, Xinglei Liu ${ }^{2}$, Weicheng $\mathrm{Li}^{2}$, Ningsheng Cai ${ }^{1}$, Sina Tebianian ${ }^{3}$, Stéphane Bertholin $^{3}$, Mahdi Yazdanpanah ${ }^{4}$, Aoling Zhang ${ }^{4}$

${ }^{1}$ Key Laboratory for Thermal Science and Power Engineering of Ministry of Education, Department of Energy and Power Engineering, Tsinghua University, Beijing 100084, China

${ }^{2}$ Clean Combustion and Flue Gas Purification Key Laboratory of Sichuan Province, Dongfang

Boiler Co., Ltd., Dongfang Electric Group, Zigong 643099, Sichuan, China

${ }^{3}$ IFP Énergies nouvelles, Rond-point échangeur de Solaize, 69360 Solaize, France

${ }^{4}$ TOTAL, Research \& Technology Gonfreville (TRTG), 76700 Harfleur, France

Corresponding Author: E-mail: lizs@mail.tsinghua.edu.cn; Tel.: +86 010-62792478.

\begin{abstract}
A circulating turbulent fluidized bed (CTFB) connected with a riser and an annular carbon stripper (CS) is proposed to be used as a fuel reactor (FR) in chemical looping combustion. The bottom section of the FR is operated under turbulent fluidization regime which can achieve enough solid residence time and enhance the mixing of oxygen carrier with solid fuel. A 1.5 $\mathrm{MW}_{\text {th }}$ cold model of the FR was designed, constructed and tested in order to investigate the hydrodynamics of solid particles with different size. Three kinds of quartz sands with different particle sizes $\left(\mathrm{d}_{50}=122\right.$ $\mu \mathrm{m}, 249 \mu \mathrm{m}$, and $392 \mu \mathrm{m}$ ) were used as bed materials to simulate the oxygen carrier. Continuous operation with reasonable pressure balance was achieved in the cold model. The effects of important variables including gas velocity, static bed height and
\end{abstract}


particle size on the gas-solid hydrodynamics of the FR were measured and discussed. It was found that the transition velocities from bubbling to turbulent fluidization for different particles of $\mathrm{d}_{50}=122 \mu \mathrm{m}, 249 \mu \mathrm{m}$, and $392 \mu \mathrm{m}$ were measured to be $0.78 \mathrm{~m} / \mathrm{s}$, $0.95 \mathrm{~m} / \mathrm{s}$ and $1.06 \mathrm{~m} / \mathrm{s}$ respectively, indicating the transition velocity increased with increasing particle size. The solid fraction profile along reactor height and solid circulation rate were affected by gas velocity and static bed height. A modified correlation was proposed to predict the solid fraction of the annular CS dilute phase, and the predicted results agree well with the experimental data under wide range of operational conditions.

Keywords: chemical looping combustion; fuel reactor; circulating turbulent fluidized bed; hydrodynamics; transition velocity; solid circulation rate; 


\section{Highlight:}

1. A circulating turbulent fluidized bed (CTFB) connected with a riser and an annular carbon stripper is proposed to be used as a fuel reactor in chemical looping combustion.

2. A $1.5 \mathrm{MW}_{\text {th }}$ circulating turbulent fluidized bed fuel reactor was designed, constructed and tested.

3. The transition velocity increased with increasing particle size.

4. A modified correlation was developed for better predicting the solid fraction of dilute phase. 


\section{Introduction}

Solid fuel chemical looping combustion (CLC) is recognized as a promising combustion technology, because it can realize inherent $\mathrm{CO}_{2}$ separation from the flue gas without the need for an additional $\mathrm{CO}_{2}$ separation unit that has an energy penalty ${ }^{1}$. The CLC unit consists of a fuel reactor (FR) and an air reactor (AR), and oxygen carriers circulate continuously between the AR and FR to transfer oxygen from air to fuel. This technology avoids direct contact between the solid fuel and air, so the flue gas from FR is primarily composed of $\mathrm{CO}_{2}$ and $\mathrm{H}_{2} \mathrm{O}$, and a high-purity $\mathrm{CO}_{2}$ can be obtained after steam condensation ${ }^{2}$.

Although the solid fuel CLC technology has been highly developed in recent decades ${ }^{3-5}$, it still faces two challenges: 1) char conversion and carbon capture efficiency are relatively low owing to short solid residence time in the FR; 2) syngas conversion efficiency is not high enough and the oxygen demand for unburnt gas is high owing to the low oxygen carrier fraction in the FR dilute region. For example, Linderholm et al. ${ }^{6}$ reported the solid fuel conversion was $54.1 \% \sim 73.4 \%$ in the 100 $\mathrm{kW}_{\text {th }}$ CLC pilot plant, indicating about $36 \%$ char were unconverted and escaped from the FR. Ohlemüller et al. ${ }^{7}$ reported that the carbon capture efficiency and the syngas conversion efficiency were $43 \% \sim 55 \%$ and $61 \% \sim 73 \%$ respectively in Darmstadt 1 $\mathrm{MW}_{\text {th }}$ CLC pilot plant, indicating about 50\% char burnt in the AR and about 33\% combustible gas was unconverted. Abdulally et al. ${ }^{8}$ reported the oxygen demand of FR unburnt gas was $15 \% \sim 20 \%$ in Alstom $3 \mathrm{MW}_{\text {th }}$ CLC pilot plant, so the CLC 
advantages with inherent $\mathrm{CO}_{2}$ separation could not be achieved.

To solve above challenges, different FR configurations were proposed by different scholars ${ }^{9-20}$. Bayham et al. ${ }^{9}$ proposed using a moving bed as the FR in the $25 \mathrm{~kW}_{\text {th }}$ hot model at Ohio State University, the carbon capture efficiency, char conversion and syngas conversion efficiency were $94.9 \%, 99.9 \%$ and $99.8 \%$ respectively. However, large cross-section, uniform coal distribution and temperature homogeneity are still the challenges for the scale-up of moving bed ${ }^{10}$. Vienna University of Technology ${ }^{11}$ proposed a modification of the fuel reactor to include wedged-ring-type internals that increased the total bed inventory. Lynfelt and Leckner 12 proposed and patented a new fuel feed called "volatile distributor" to the fuel reactor, aimed at assuring a good distribution of volatiles across the cross-section of FR. Different Carbon stripers (CSs) were proposed by Chalmers University of Technology ${ }^{13}$, Darmstadt University of Technology ${ }^{14}$, ICB-CSIC ${ }^{15}$, Tsinghua University ${ }^{16-20}$ and IFPEN ${ }^{21}$, and the CS can efficiently separate the unconverted char from oxygen carrier, so the total char residence time in the FR is increased to achieve high carbon capture efficiency.

In this work, a circulating turbulent fluidized bed (CTFB) consisting of a dense region connected to a riser is proposed to be used as a fuel reactor, and the turbulent fluidization regime is chosen to achieve enough solid residence time and enhance the mixing of oxygen carrier with solid fuel. An annular CS is proposed to be used as a second fuel reactor because it can not only separate the char from oxygen carrier, but also improve the unburnt gas conversion ${ }^{19,21}$. A $1.5 \mathrm{MW}_{\text {th }}$ cold model was designed, 
constructed and operated to evaluate the hydrodynamics of the FR. Quartz sands with different particle sizes were used as bed materials to simulate the oxygen carrier, and a stable operation with reasonable pressure balance was achieved. The turbulent characteristics including the transition velocity from bubbling to turbulent fluidization, solid fraction profile and solid circulation were measured. The effects of gas velocity, static bed height and particle size on the hydrodynamics were studied. A modified correlation was proposed to predict the solid fraction of the annular CS dilute region.

\section{Experiments}

\subsection{Experimental apparatus}

The cold model system consists of a fuel reactor, air supply system, feeding system and gas filter system, as shown in Figure 1. The fuel reactor is a circulating turbulent fluidized bed consisting of a dense region connected to a riser and an annular CS, and the total height of unit is $10.45 \mathrm{~m}$. The FR with a square structure (i.e. the length is equal to the width) is designed, and the sectional sizes of turbulent fluidized bed (TFB), FR riser, and annular CS are $0.6 \mathrm{~m}, 0.25 \mathrm{~m}$ and $0.7 \mathrm{~m}$, respectively. The FR riser is inserted into the annular CS at a depth of $1 \mathrm{~m}$ in order to form a dense phase in the annular CS. Based on the total volume of the FR and particle density, the total bed inventory of the FR is calculated to be $\sim 750 \mathrm{~kg}$. Lyngfelt and Leckner ${ }^{22}$ pointed out that the bed inventory of the FR was $500 \mathrm{~kg} / \mathrm{MW}_{\text {th }}$ in the $1000 \mathrm{MW}_{\text {th }}$ solid-fuel CLC design. Therefore, the cold model in this work corresponds approximately to $1.5 \mathrm{MW}_{\text {th. }}$. 
The solid particles are fed into the turbulent fluidized bed from the feeding system until the bed inventory of the FR meets the experiment requirements. After a certain residence time, the solid particles in the turbulent fluidized bed are elutriated into the FR riser which is transport regime. Subsequently, the solid particles are transported into the annular CS and then enter into a high-efficiency cyclone which separate the solid particles from outlet gas stream, and the solid particles pass through the cyclone dipleg and loop seal (LS) and return back to the turbulent fluidized bed. The dense phase height of the annular CS is appropriately equal to the depth of the FR riser inserted into the annular CS, while the dense phase height of the turbulent fluidized bed varies with the total bed inventory of the FR. Total 18 pressure ports are installed on the cold model system for measuring pressure profiles. A bufferfly valve is installed on the cyclone dipleg to measure the solid circulation rate.

The fluidizing air for the cold model is supplied by a Roots blower and an air compressor, as shown in Figure 1. The fluidizing airs required for the turbulent fluidized bed and annular CS are provided by the Roots blower. Two pneumatic valves are used to control the fluidizing air amount of the turbulent fluidized bed $\left(100 \sim 1500 \mathrm{~m}^{3} / \mathrm{h}\right)$ and the fluidizing air amount of the annular CS $\left(200 \sim 400 \mathrm{~m}^{3} / \mathrm{h}\right)$. Meanwhile, in order to feed the solid particles into the turbulent fluidized bed smoothly, a pressure balance air is designed. The air streams for loop seal are controlled by the air compressor, and the flowrates are measured by two float flowmeters, as shown in Figure 1. 


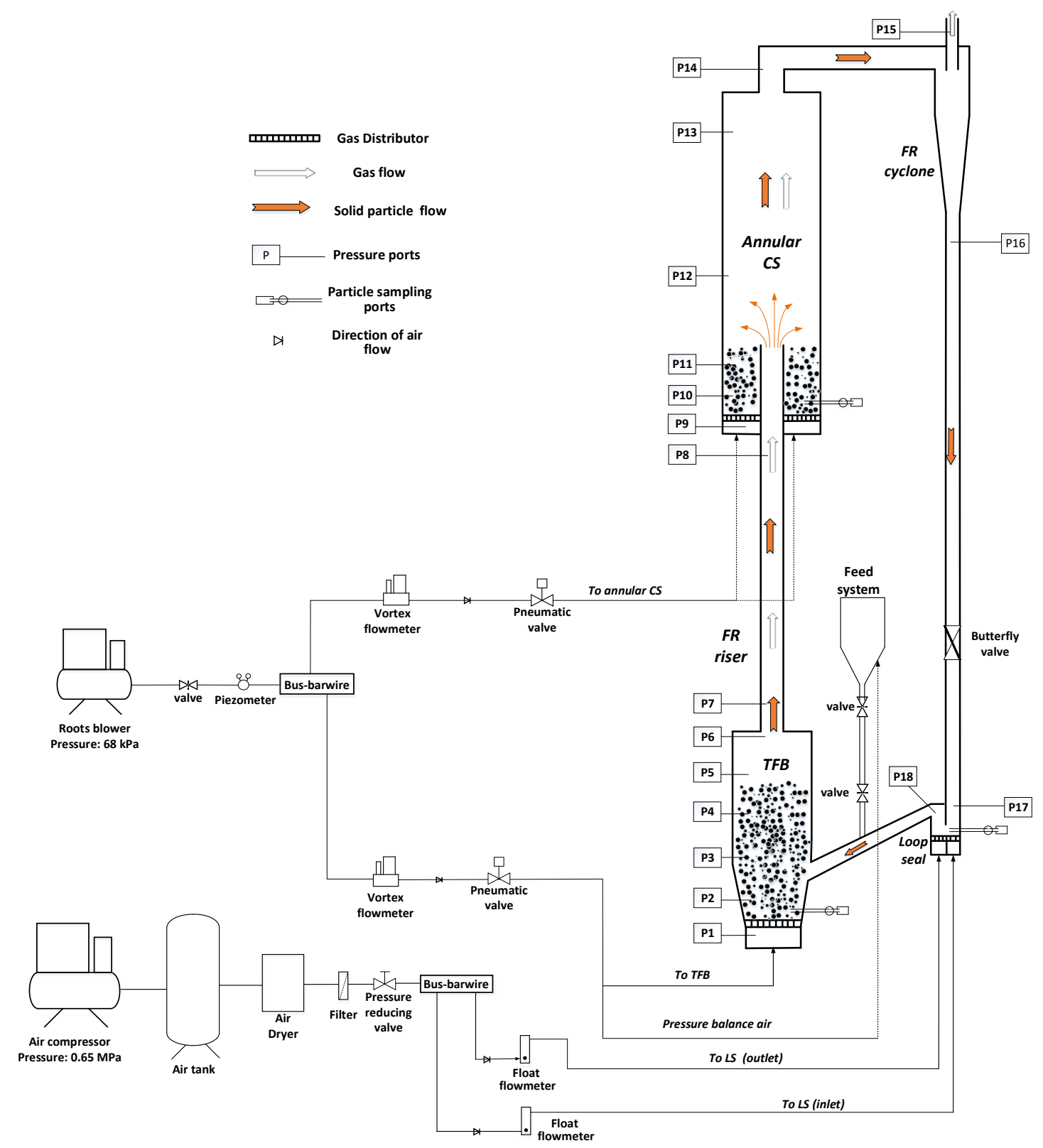

Figure 1. Diagram of the cold model system

\subsection{Material}

Three different size quartz sands $\left(\mathrm{d}_{50}=122 \mu \mathrm{m}, 249 \mu \mathrm{m}\right.$, and $\left.392 \mu \mathrm{m}\right)$, which belong to Geldart B particles, are chosen as bed materials, and the particle size distributions (PSD) and properties are shown in Figure 2 and Table 1, respectively. 


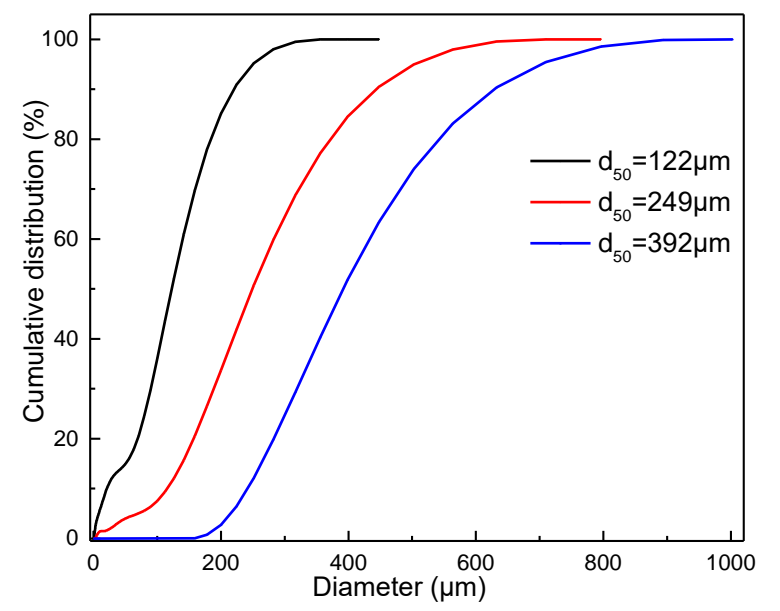

Figure 2. Particle size distributions of three quartz sands

Table 1. The properties of three quartz sands

\begin{tabular}{ccccc}
\hline Item & Unit & $\mathrm{d}_{50}=122 \mu \mathrm{m}$ & $\mathrm{d}_{50}=249 \mu \mathrm{m}$ & $\mathrm{d}_{50}=392 \mu \mathrm{m}$ \\
\hline Particle density & $\mathrm{kg} / \mathrm{m}^{3}$ & 2715 & 2716 & 2701 \\
Bulk density & $\mathrm{kg} / \mathrm{m}^{3}$ & 1396 & 1390 & 1377 \\
Archimedes number & - & 178 & 1512 & 5870 \\
Classification of Geldart & - & B & B & B \\
\hline
\end{tabular}

The physical properties of quartz sand and oxygen carrier are mainly different in particle size and density from the hydrodynamics perspective. The particle size of the oxygen carrier used in the CLC unit is generally $100 \sim 300 \mu \mathrm{m}^{23}$, which is consistent with the selected size range of quartz sand. The particle density for different oxygen carriers is different and the range is generally $2500 \sim 4400 \mathrm{~kg} / \mathrm{m}^{324,25}$. Additionally, the particle density of fresh oxygen carrier and activated oxygen carrier may be different, for example, the particle density of fresh ilmenite is $3980 \mathrm{~kg} / \mathrm{m}^{3}$, while that of activated ilmenite is changed to $2760 \mathrm{~kg} / \mathrm{m}^{326}$. This shows that it is impossible to find a suitable solid particle to represent all kinds of oxygen carriers, but an empirical correlation considering the effect of particle density should be used. The particle 
density of quartz sand is $\sim 2700 \mathrm{~kg} / \mathrm{m}^{3}$, which is close to the particle density of activated ilmenite and other light oxygen carriers. The main purpose of using quartz sand as bed materials is to obtain the empirical correlation which take into account the effect of particle density of solid particles. After obtaining the empirical correlation, the fluidization characteristics of oxygen carrier with different particle density can be predicted.

\subsection{Data evaluation}

The solid fraction $\left(\varepsilon_{s}\right)$ is calculated by pressure drop and is shown in equation (1):

$$
\Delta P_{i-j}=\rho_{p} \varepsilon_{s} g \Delta H_{i-j}
$$

where $\Delta P_{i-j}$ represents the pressure drop from port $i$ to port $j, \mathrm{~Pa} ; \Delta H_{i-j}$ represents the height from port $i$ to port $j, \mathrm{~m} ; \rho_{p}$ represents the particle density, $\mathrm{kg} / \mathrm{m}^{3} ; g$ is the gravity acceleration, $\mathrm{m} / \mathrm{s}^{2}$.

Solid circulation rate is measured by accumulative material method. A bufferfly valve is installed on the cyclone dipleg. When the operation of cold model system is dynamically stable, the bufferfly valve is closed and the accumulated height of solid particles and the elapsed time in the cyclone dipleg are measured. Combined with equation (2), the solid circulation rate ( $G_{s}$ ) can be calculated.

$$
G_{s}=\frac{\rho_{b} S_{\text {pipe }} H_{\text {pipe }}}{S_{C S} t_{\text {pipe }}}
$$

where $\rho_{b}$ is the bulk density, $\mathrm{kg} / \mathrm{m}^{3} ; S_{\text {pipe }}$ is the sectional area of the cyclone dipleg, $\mathrm{m}^{2} ; H_{\text {pipe }}$ is the accumulated height of quartz sand in the cyclone dipleg, $\mathrm{m} ; S_{C S}$ is 
the sectional area of the annular CS; $t_{\text {pipe }}$ is the elapsed time of quartz sand accumulation in the cyclone dipleg, s.

Standard deviation $(\sigma)$ is used to assess the pressure fluctuation of cold model system:

$$
\sigma=\sqrt{\frac{1}{N} \sum_{i=1}^{N}\left(P_{i}-P_{a v e}\right)}
$$

where $N$ represents the number of pressure drops, -; $P_{i}$ represents the pressure drop at number $i, \mathrm{kPa} ; P_{\text {ave }}$ represents the average pressure drop, $\mathrm{kPa}$.

\section{Results and discussion}

\subsection{Stable operation}

A stable and continuous operation is the basis of cold model and experimental study. By measuring the pressure drop of the turbulent fluidized bed, its pressure fluctuation results under different static bed heights $\left(\mathrm{d}_{50}=122 \mu \mathrm{m}, \mathrm{u}_{\mathrm{FR}}=0.78 \mathrm{~m} / \mathrm{s}\right)$ are shown in Figure 3. The pressure drops of the turbulent fluidized bed under three static bed heights were dynamically stable, and this indicated the system hydrodynamics was stable and there was no particles loss. The bag filter behind the cold model did not collect solid particles during the experiment, which also indicated that the bed materials did not escape from the FR cyclone, because the design principle of high-efficiency cyclone is adopted by the FR cyclone. Bed inventory has a big effect on the pressure fluctuation, and the pressure fluctuation increases with the increase of bed inventory. For example, when the static bed height increased from $0.75 \mathrm{~m}$ to 1.25 
$\mathrm{m}$, the pressure fluctuation of $7.2 \sim 9.5 \mathrm{kPa}$ at $0.75 \mathrm{~m}$ static bed height increased to $12.0 \sim 15.5 \mathrm{kPa}$ at $1.2 \mathrm{~m}$ static bed height, and the standard deviation of pressure increased from $0.38 \mathrm{kPa}$ to $0.64 \mathrm{kPa}$. This is because the bubble size increases with the increase of static bed height ${ }^{27}$, and dynamic pressure loss caused by the bubble eruption on bed surface results in an obvious pressure fluctuation.

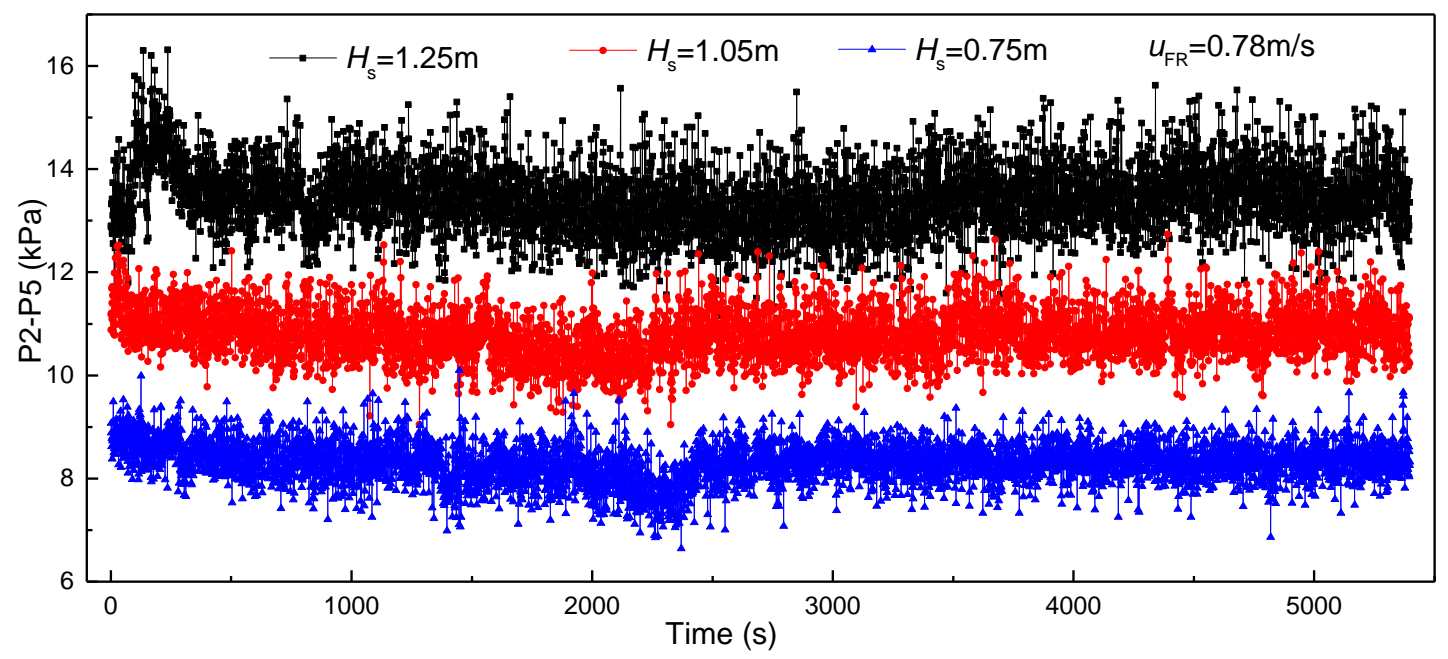

Figure 3. Pressure fluctuation of turbulent fluidized bed versus time $\left(d_{50}=122 \mu \mathrm{m}\right)$

Pressure profile along reactor height is shown in Figure 4, and a reasonable pressure balance was achieved in the cold model system. The pressure drops in the dense phase of the turbulent fluidized bed (P1-P5) and the annular CS (P9-P12) were $\sim 12 \mathrm{kPa}$ and $\sim 10 \mathrm{kPa}$ respectively, indicating most of particles accumulated there. It should be noted that the values of P1-P2 and P9-P10 included not only the pressure drops of solid particles, but also the pressure drops of the turbulent fluidized bed distributor $(0.4 \mathrm{kPa})$ and the annular $\mathrm{CS}$ distributor $(2.3 \mathrm{kPa})$. The pressure drops in the FR riser (P7-P8) and the dilute phase of the annular CS (P12-P13) were smaller than $0.5 \mathrm{kPa}$, and this indicated the solid fraction in the dilute phase was very low. The loop seal is critical for the pressure balance of cold model system, and pressure 
drops of the loop seal (P17-P18, P18-P4) were all positive, indicating no gas back leakage from turbulent fluidized bed to cyclone by passing through the loop seal.

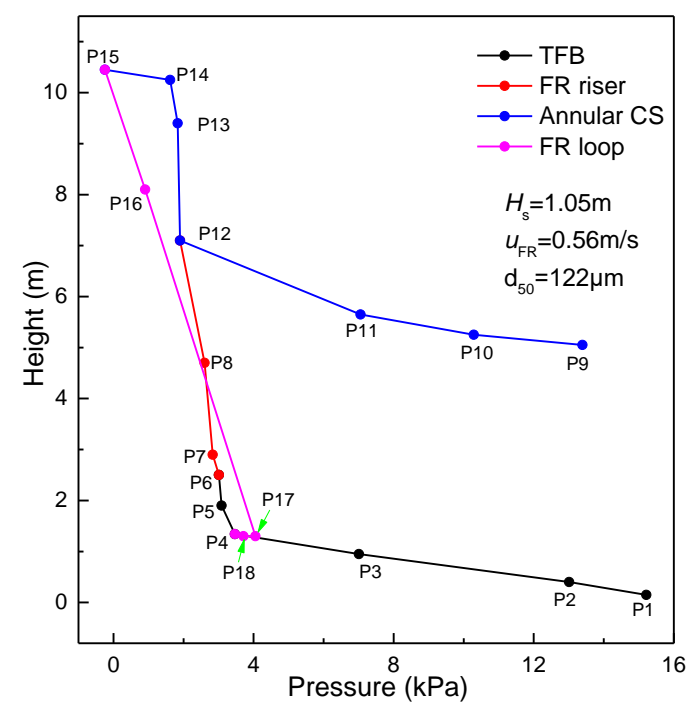

Figure 4. Pressure profile of cold model system

\subsection{Effect of particle size on transition velocity}

For the turbulent fluidized bed, an important parameter is the transition velocity $\left(U_{\mathrm{c}}\right)$ which is defined the transition velocity from bubbling to turbulent fluidization ${ }^{28}$. Various methods, including capacitance signals, visual observations, optical fiber probes, bed expansion and pressure fluctuation, have been used to determine $U_{\mathrm{c}}{ }^{29}$. Herein, pressure fluctuation method is adopted to measure $U_{\mathrm{c}}$. The gas velocity at the maximum standard deviation of pressure fluctuation corresponds to the beginning of the transition to turbulent fluidization. Both pressure drop fluctuations (two points) and absolute pressure fluctuations (single point) have been proposed to study the transition to turbulent fluidization and the former was used as the measurement method in this work. P2-P3 was selected as the measurement point of pressure fluctuations. The static bed height was adjusted to $1.1 \mathrm{~m}$ before the start of the 
measurement, which ensured that the average pressure drop of P2-P3 maintained at about $6 \mathrm{kPa}$ during the whole measurement process, eliminating the influence of the variation of standard deviation caused by the change of bed inventory.

The standard deviation of pressure fluctuations versus gas velocity for different particle sizes is shown in Figure 5. With the increase of gas velocity, the standard deviation increased rapidly and reached the maximum value, and then decreased. The initial increase of the standard deviation is attributed to the increase in the bubble size mainly caused by bubble coalescence, while the decrease of the standard deviation is a result of bubbles splitting into small bubbles or voids after attaining their largest size at the gas velocity corresponding to the maximum standard deviation. The transition velocities for particle with size of $\mathrm{d}_{50}=122 \mu \mathrm{m}, 249 \mu \mathrm{m}$, and $392 \mu \mathrm{m}$ were $0.78 \mathrm{~m} / \mathrm{s}$, $0.95 \mathrm{~m} / \mathrm{s}$ and $1.06 \mathrm{~m} / \mathrm{s}$ respectively, indicating the transition velocity increased with increasing particle size.

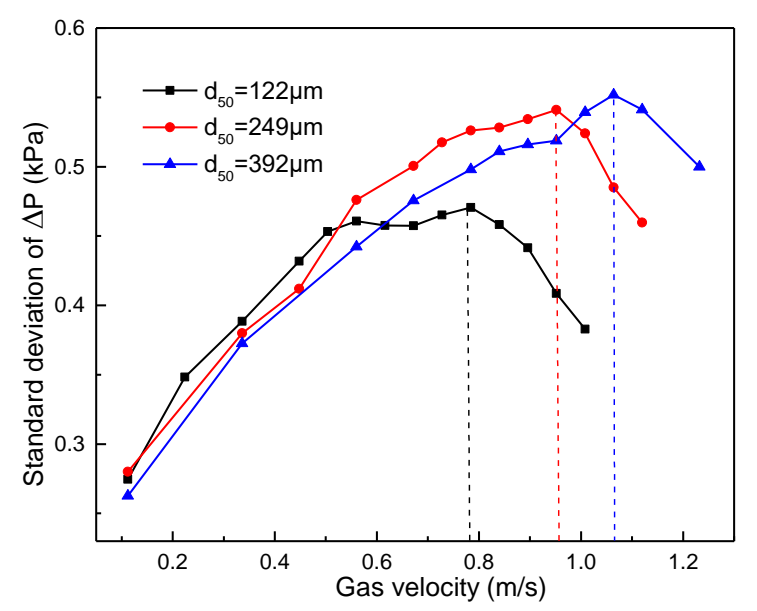

Figure 5. Effect of gas velocity on the standard deviation of $\Delta P$

A number of empirical correlations have been proposed to predict the transition velocity ${ }^{28,30-38}$, as listed in Table 2 . The experimental data measured in this study were used to validate the feasibility of empirical correlations, and the results are 
shown in Figure 6. The calculated results by Bi and Grace's (APF) correlation and Rim and Lee's correlation were in agreement with the experimental data, and the average relative deviations were $5.96 \%$ and $9.08 \%$ respectively, while other empirical correlations overestimated the transition velocity. The overestimation is mainly caused by the following two reasons. Frist, many empirical correlations are fitted by experimental data of Geldart A particles, while the particles used in this work belong to Geldart B particles. The hydrodynamics of Geldart A and Geldart B particles are different, so the empirical correlations based on Geldart A particles can not accurately predict the transition velocity of Geldart B particles. Additionally, Cai et al. ${ }^{39}$ had reported the transition velocity decreased with the increase of reactor diameter. The equivalent diameter of current reactor used in this work $(0.6 \mathrm{~m})$ is higher than that of published literatures, in which the value is generally between $0.02 \sim 0.3 \mathrm{~m}^{28,33,37,40}$.

Table 2. Typical empirical correlations for the transition velocity

\begin{tabular}{|c|c|}
\hline Author (s) & Correlation (s) \\
\hline Yerushalmi and Cankurt 30 & $U_{c}=3.0\left(\rho_{p} d_{p}\right)^{0.5}-0.77$ \\
\hline Jin et al. ${ }^{31}$ & $U_{c} / \sqrt{g d_{p}}=\left(f \frac{D_{t}}{d_{p}} \frac{\rho_{p}-\rho_{g}}{\rho_{g}}\right)^{0.27}$ \\
\hline Lee and $\mathrm{Kim}^{32}$ & $\operatorname{Re}_{c}=0.700 A r^{0.485}$ \\
\hline Cai et al. ${ }^{33}$ & $U_{c} / \sqrt{g d_{p}}=\left(\frac{\mu_{g 20}}{\mu_{g}}\right)^{0.2}\left[\left(\frac{0.211}{D_{t}^{0.27}}+\frac{0.00242}{D_{t}^{1.27}}\right)^{1 / 0.27}\left(\frac{\rho_{g 20}}{\rho_{g}}\right)\left(\frac{\rho_{p}-\rho_{g}}{\rho_{g}}\right)\left(\frac{D_{t}}{d_{p}}\right)\right]^{0.27}$ \\
\hline Horio 34 & $R e_{c}=0.936 A r^{0.472}$ \\
\hline Nakajima et al. ${ }^{35}$ & $R e_{c}=0.663 A r^{0.467}$ \\
\hline Dumham et al. ${ }^{36}$ & $\begin{array}{l}\operatorname{Re}_{c}=1.201 A r^{0.386}\left(H / D_{t}\right)^{0.18 \ln \left(\rho_{p} d_{p}\right)+0.264} ; \text { for Group A and B particles } \\
\operatorname{Re}_{c}=1.027 A r^{0.450}\left(H / D_{t}\right)^{0.18 \ln \left(\rho_{p} d_{p}\right)+0.264} ; \text { for Group D particles }\end{array}$ \\
\hline
\end{tabular}




$$
\begin{array}{cc}
\text { Bi and Grace (DPF) }{ }^{37} & \operatorname{Re}_{c}=1.243 A r^{0.447} \\
\text { Bi and Grace (APF) }{ }^{37} & \operatorname{Re}_{c}=0.565 A r^{0.461} \\
\text { Yazdanpanah et al. }{ }^{38} & \operatorname{Re}_{c}=0.21 A r^{0.49} \\
\text { Rim and Lee }{ }^{28} & \operatorname{Re}_{c}=0.465 A r^{0.489}\left(1+\frac{\sigma_{p}}{\Delta d_{p}}\right)^{-0.206} \\
& \Delta d_{p}=d_{p 84 \%}-d_{p 16 \%}
\end{array}
$$

Note: $d_{p}$ is the particle diameter, $\mathrm{m} ; D_{t}$ is the bed diameter, $\mathrm{m} ; \rho_{g}$ is the density of fluidizing gas, $\mathrm{kg} / \mathrm{m}^{3} ; R e_{c}$ is the Reynolds number based on $R e_{c}=d_{p} U_{c} \rho_{g} / \mu_{g},-; A r$ is the Archimedes number, -; $\mu_{g}$ is the gas viscosity, $\mathrm{kg} /(\mathrm{m} \cdot \mathrm{s}) ; H$ is the expanded bed height, $\mathrm{m} ; \sigma_{p}$ is the standard deviation of particle size distribution, $\mathrm{m} ; d_{p i \%}$ particle diameter at $i \%$ in the cumulative distribution, $\mathrm{m}$.

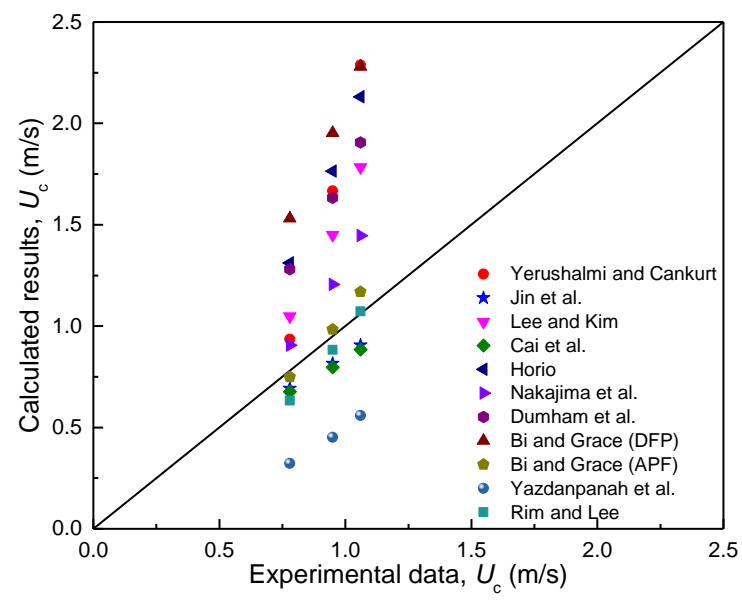

Figure 6. Comparison between the calculated results from empirical correlations and the

\section{experimental data}

\subsection{Effect of operational conditions on fluidization characteristics}

The solid fraction profile along reactor height was studied, and the effect of gas velocity, static bed height and particle size on the solid fraction is shown in Figure 7 (a)-(c). The turbulent fluidized bed can be divided into the dense phase and dilute 
phase, and the dense bed height decreased with the increase of gas velocity, and more particles were elutriated into the freeboard region. When the gas velocity was lower than the transition velocity $(0.78 \mathrm{~m} / \mathrm{s})$, the solid fraction decreased slowly with the increase of gas velocity, as shown in Figure 7(a). While the gas velocity was bigger than the transition velocity, the effect of gas velocity on the solid fraction profile was more obvious because the fluidized bed regime changes from bubbling regime to turbulent regime and more solid particles are transported into the FR riser and annular CS. The results showed that the fluidization characteristics before and after the transition velocity were different, and the solid carrying capacity under the turbulent regime was more obvious than that under the bubbling regime.

The bed inventory had a big effect on the dense bed height and the dense phase height increased with the increase of bed inventory, while the freeboard height decreased with the bed inventory, and the flow of solid particles through elutriation increased, so the solid fraction at the outlet of the turbulent fluidized bed increased, as shown in Figure 7(b). In the freeboard region, the pressure drop increased with the increase of bed inventory, therefore, its solid fraction increased with the increase of bed inventory. From Figure 7(c), with the increase of particle size, the solid fraction at the outlet of the turbulent fluidized bed decreased owing to the reduction of elutriation capacity for big particle size. At the same gas velocity of $0.78 \mathrm{~m} / \mathrm{s}$, the operation was in the turbulent regime for $\mathrm{d}_{50}=122 \mu \mathrm{m}$, while the operation was in the bubbling regime for $\mathrm{d}_{50}=249 \mu \mathrm{m}$ and $392 \mu \mathrm{m}$, and more solid particles were elutriated into the FR riser and annular CS for $\mathrm{d}_{50}=122 \mu \mathrm{m}$, so the dense phase height of $\mathrm{d}_{50}=122 \mu \mathrm{m}$ 
was lower that of $\mathrm{d}_{50}=249 \mu \mathrm{m}$ and $392 \mu \mathrm{m}$. The pressure drop for $\mathrm{d}_{50}=122 \mu \mathrm{m}$ in the freeboard region was lower than that for $\mathrm{d}_{50}=249 \mu \mathrm{m}$ and $392 \mu \mathrm{m}$, so the solid fraction of the freeboard region for $\mathrm{d}_{50}=122 \mu \mathrm{m}$ was the lowest. The sectional area of the FR riser was less than that of the turbulent fluidized bed and there was a sharp connection between the turbulent fluidized bed and the FR riser, resulting in an obvious particle backflow phenomenon. Therefore, the solid fraction at the outlet of the turbulent fluidized bed was higher than that of the dilute phase of the turbulent fluidized bed, as shown in Figure 7(a)-(c).

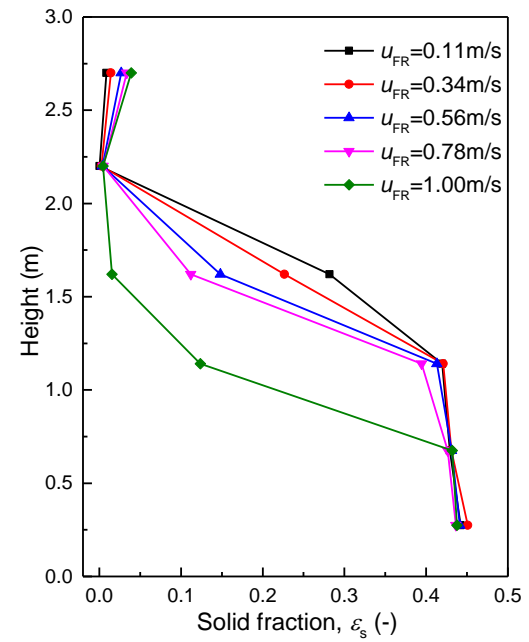

(a)

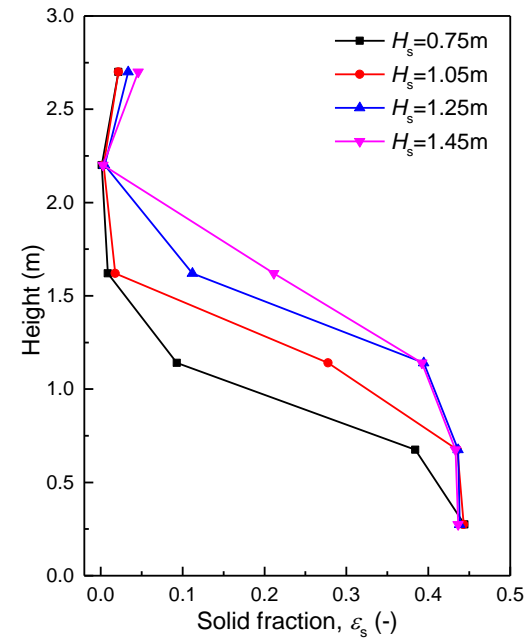

(b)

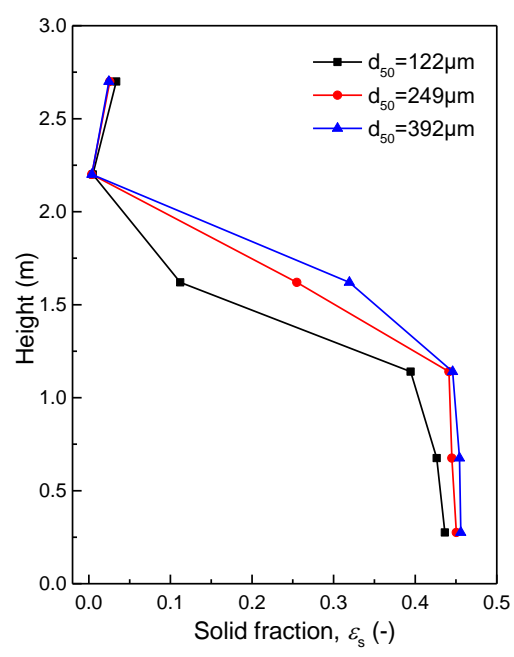

(c) 
Figure 7. The solid fraction profile at different gas velocity, static bed height and particle size: (a) $\mathrm{d}_{50}=122 \mu \mathrm{m}, H_{\mathrm{s}}=1.25 \mathrm{~m}$; (b) $\mathrm{d}_{50}=122 \mu \mathrm{m}, u_{\mathrm{FR}}=0.78 \mathrm{~m} / \mathrm{s}$; (c) $H_{\mathrm{s}}=1.25 \mathrm{~m}, u_{\mathrm{FR}}=0.78 \mathrm{~m} / \mathrm{s}$.

Different empirical correlations reported from published literatures were used to predict the solid fraction of dense phase ${ }^{39,41-44}$, as shown in Table 3. The comparison of the calculated results by different empirical correlations and the typical experimental data are shown in Figure 8. The average relative error between the calculated results by King's correlation and the experimental data was minimum, indicating the calculated results by King's correlation were closest to the experimental data. So, King's correlation could be used to predict the dense phase solid fraction of Geldart B particles in the fuel reactor.

Table 3. Typical empirical correlations for the solid fraction of dense phase

\begin{tabular}{cc}
\hline Author (s) & Correlation (s) \\
\hline King ${ }^{4}$ & $\varepsilon_{s d}=1-\frac{u_{g}+1}{u_{g}+2}$ \\
Cai ${ }^{39}$ & $\varepsilon_{s d}=1-\left(0.796+0.00894 / D_{t}\right) *\left(\frac{\mathrm{Re}_{p}{ }^{3}}{A r^{2}}\right)^{0.0653}$ \\
Monazam and Shadle 42 & $\varepsilon_{s d}=0.005^{*}\left(\frac{u_{s}}{u_{g}}\right)^{1.045}\left(\frac{D_{t}}{d_{p}}\right)^{0.541}\left(\frac{\rho_{g} u_{g} d_{p}}{\mu_{g}}\right)^{0.915}$ \\
Miao et al. ${ }^{43}$ & $\varepsilon_{s d}=1.0422\left(\frac{G_{\mathrm{s}}}{\rho_{p}\left(u_{g}-u_{t}\right)}\right)^{0.2781}\left(\frac{u_{g}}{\sqrt{g D_{t}}}\right)^{-0.3218}\left(\frac{\rho_{g} u_{t} d_{p}}{\mu_{g}}\right)^{-0.1195}$ \\
Wong et al. ${ }^{44}$ & $\varepsilon_{s d}=1-0.25\left(\frac{G_{\mathrm{s}}}{\rho_{p} u_{g}}\right)^{-0.11} D_{t}^{-0.23}\left(\frac{\rho_{g} u_{t} d_{p}}{\mu_{g}}\right)^{0.02} ;$ for group B solids \\
\hline
\end{tabular}

Note: $\varepsilon_{s d}$ is the solid fraction of dense phase, $-; u_{g}$ is the fluidizing gas velocity, $\mathrm{m} / \mathrm{s} ; u_{s}$ is the solid velocity, $\mathrm{m} / \mathrm{s} ; u_{t}$ is the terminal velocity, $\mathrm{m} / \mathrm{s}$. 


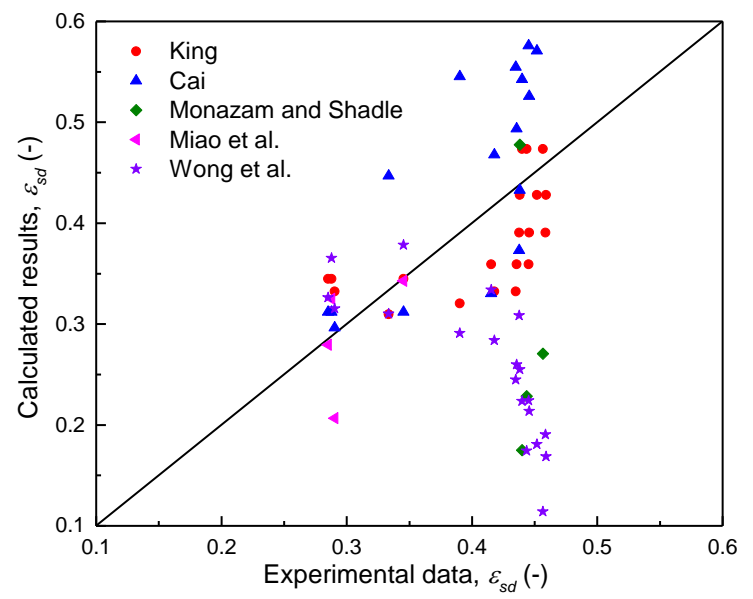

Figure 8. Comparison between the calculated results and the typical experimental data

\subsection{Effect of operational conditions on solid circulation rate}

The effect of gas velocity and static bed height on the solid circulation rate is depicted in Figure 9. Under constant static bed height, with the increase of gas velocity from $0.11 \mathrm{~m} / \mathrm{s}$ to $0.78 \mathrm{~m} / \mathrm{s}$, the solid circulation rate increased slowly; when the gas velocity increased from $0.78 \mathrm{~m} / \mathrm{s}$ to $1.23 \mathrm{~m} / \mathrm{s}$, the solid circulation rate increased obviously. As mentioned above, $0.78 \mathrm{~m} / \mathrm{s}\left(\mathrm{d}_{50}=122 \mu \mathrm{m}\right)$ is the transition velocity, that is to say, the FR with gas velocity less than $0.78 \mathrm{~m} / \mathrm{s}$ is the bubbling bed and higher than $0.78 \mathrm{~m} / \mathrm{s}$ is the turbulent bed. Different fluidized bed regimes have different fluidization characteristics, and the elutriation capacity in the turbulent regime is significantly greater than that in the bubbling regime. When the gas velocity remained unchanged, the solid circulation rate increased with the static bed height raised from $0.75 \mathrm{~m}$ to $1.05 \mathrm{~m}$ because obviously the freeboard height was smaller. However, the solid circulation rate almost remained constant when the static bed height increased from $1.05 \mathrm{~m}$ to $1.45 \mathrm{~m}$, because the saturated carrying capacity of gas in the dilute phase of the annular CS has been reached and no longer changes with 
the increase of static bed height. By comparing the effects of gas velocity and static height on the solid circulation rate, it was found that the solid circulation rate was more affected by the gas velocity.

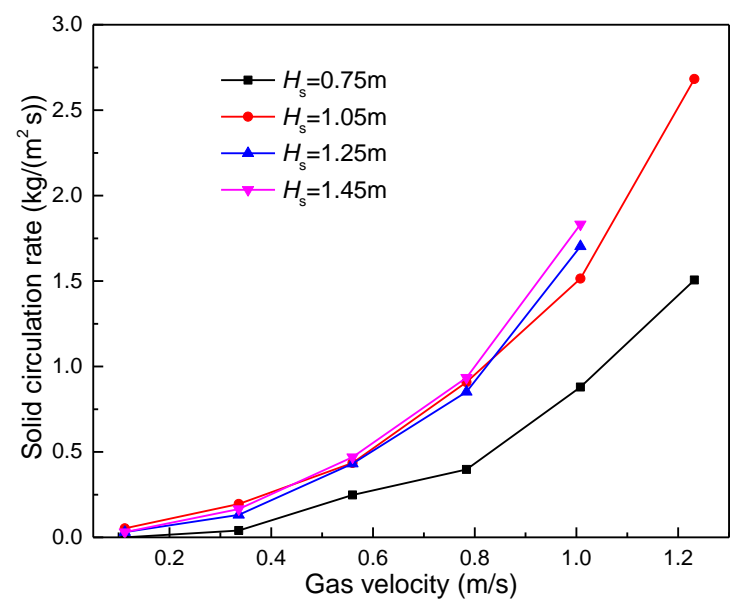

Figure 9. Effect of gas velocity and static bed height on the solid circulation rate $\left(d_{50}=122\right.$

\section{$\mu \mathbf{m})$}

The effect of gas velocity and static bed height on the solid fraction of the annular CS dilute phase is depicted in Figure 10. With the increase of gas velocity, more particles were elutriated to the annular CS dilute phase, so the solid fraction increased. With the increase of static bed height, the solid fraction of the annular CS dilute phase raised rapidly at first and then almost no obvious increase. Compared Figure 9 with Figure 10, it is found that the variation trends of the solid circulation rate and the solid fraction affected by gas velocity and static bed height are basically similar, indicating that there is a correlation between the solid circulation rate and the solid fraction of the annular CS dilute phase. 


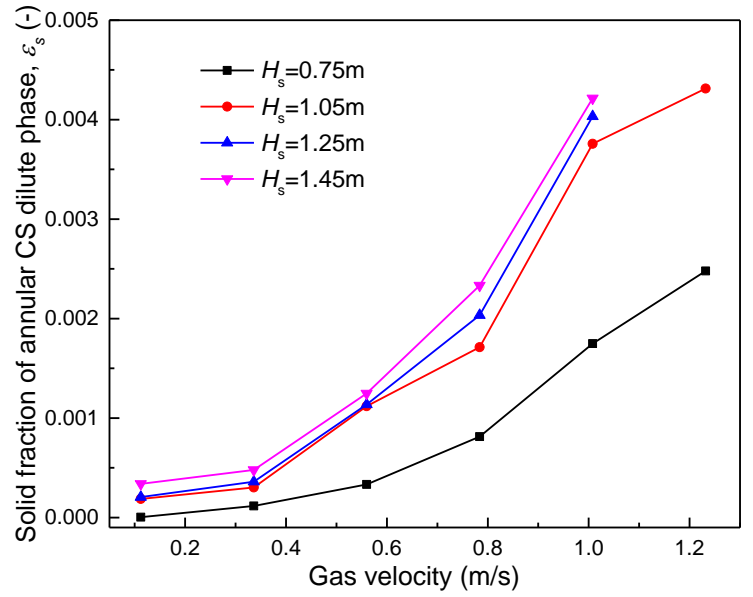

Figure 10. Effect of gas velocity and static bed height on the solid fraction of the annular CS

dilute phase $\left(d_{50}=122 \mu \mathrm{m}\right)$

The effects of particle size on the solid circulation rate and the solid fraction of the annular CS dilute phase are shown in Figure 11 and Figure 12. Under the same gas velocity, with the increase of particle size, the elutriation capacity decreased correspondingly, and the amount of particle elutriated to the annular CS dilute phase was reduced, so the solid circulation rate and the solid fraction of the annular CS dilute phase decreased.

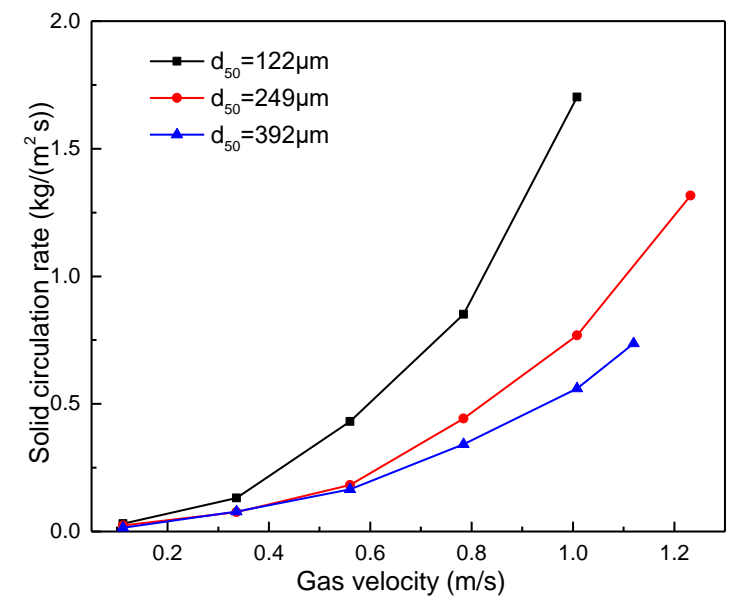

Figure 11. Effect of particle size on the solid circulation rate $\left(H_{\mathrm{s}}=1.25 \mathrm{~m}\right)$ 


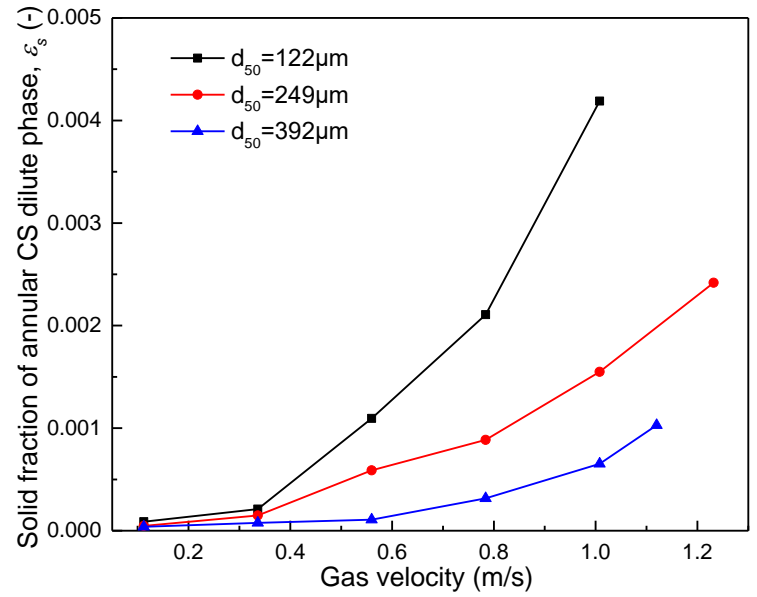

Figure 12. Effect of particle size on the solid fraction of the annular CS dilute phase $\left(H_{\mathrm{s}}=1.25\right.$

m)

Different empirical correlations proposed by different scholars have been used to predict the relationship between the solid fraction of dilute phase and the solid circulation rate ${ }^{45-53}$. Taking the solid circulation rate measured in the experiments as the independent variable, the solid fraction of dilute phase was calculated according to these correlations. The calculated results were compared with the experimental data, and the results are shown in Table 4. The average relative errors between the calculated results and the experimental data were big. This is because most of the correlations are applicable to the cases where the gas velocity is bigger than $3 \mathrm{~m} / \mathrm{s}$ (turbulent or fast bed) or the bed materials belong to Geldart A particles ${ }^{49,51-53}$. However, in this work, the gas velocity of dilute phase ranges from $0.36 \mathrm{~m} / \mathrm{s}$ to 1.23 $\mathrm{m} / \mathrm{s}$ (bubbling or turbulent bed) and the bed materials belong to Geldart B particles. The differences of gas velocity and particle properties lead to different fluidization characteristics, so it is impossible to predict accurately. The calculated results of Issangya's correlation were closest to the experimental data. However, Issangya's correlation has some limitation because it can only predict the case that the gas 
velocity is higher than the terminal velocity. Ouyang and Potter's correlation also could predict the solid fraction at different gas velocities with the average relative error of $48.90 \%$. A comparison between the typical experimental data and the results calculated by Ouyang and Potter's correlation is presented in Figure 13(a). When the gas velocity of the annular CS dilute phase was below $0.53 \mathrm{~m} / \mathrm{s}$, the calculated results matched well with the experimental data. However, when the gas velocity of the annular CS dilute phase was higher than $0.53 \mathrm{~m} / \mathrm{s}$, the calculated results were obviously not in agreement with the experimental data. Because the diameter of Ouyang and Potter's correlation $(0.05 \sim 0.4 \mathrm{~m})$ is smaller than that of the annular CS $(0.7 \mathrm{~m})$ and the gas velocity is also different, the experimental results in this work cannot well match the calculated results of Ouyang and Potter's correlation. Accordingly, the correlation proposed by Ouyang and Potter needs to be modified as follows:

$$
1-\varepsilon=5.0\left(\frac{G_{s} / \rho_{p}}{G_{s} / \rho_{p}+u_{g}}\right)
$$

The modified correlation can accurately predict the typical experimental results under various gas velocity, as shown in Figure 13(b). Correlation (4) was used to calculate the solid fraction of dilute phase under different working conditions, and the calculated results were compared with the experimental data, as shown in Figure 14. It can be seen from Figure 14 that the model predicted results were in good agreement with the experimental data. 
Table 4. Empirical correlations for the solid fraction and solid circulation rate

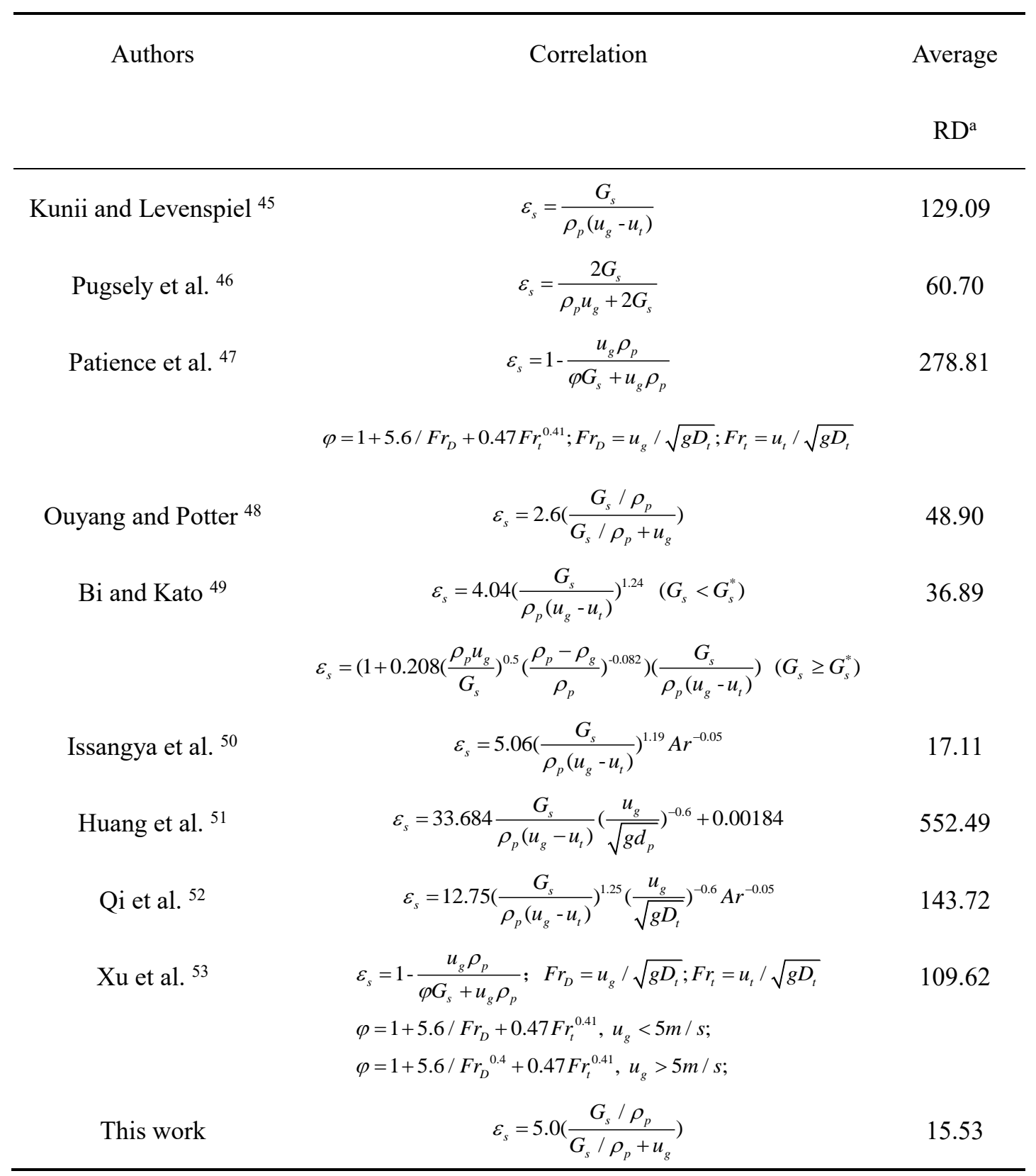

${ }^{a} \mathrm{RD}$ (relative deviation): $R D=\frac{1}{N} \frac{\sum_{i=1}^{N}\left|\left(\varepsilon_{s}\right)_{i, \text { calc }}-\left(\varepsilon_{s}\right)_{i, \text { expt }}\right|}{\left(\varepsilon_{s}\right)_{i, \text { expt }}}$

Note: $\varphi$ is the slip factor, $-; F r_{D}$ is the Froude number based on bed diameter, $-; F r_{t}$ is the particle Froude number, $-; G_{s}^{*}$ is the saturation carrying capacity, $\mathrm{kg} /\left(\mathrm{m}^{2} \cdot \mathrm{s}\right)$; 


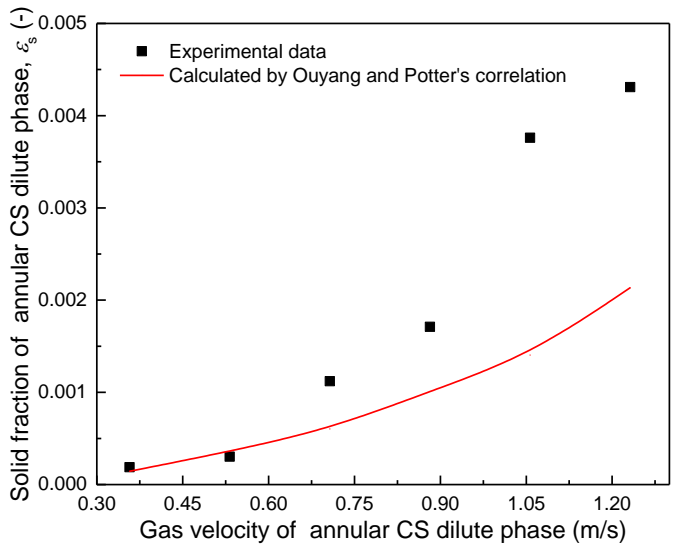

(a)

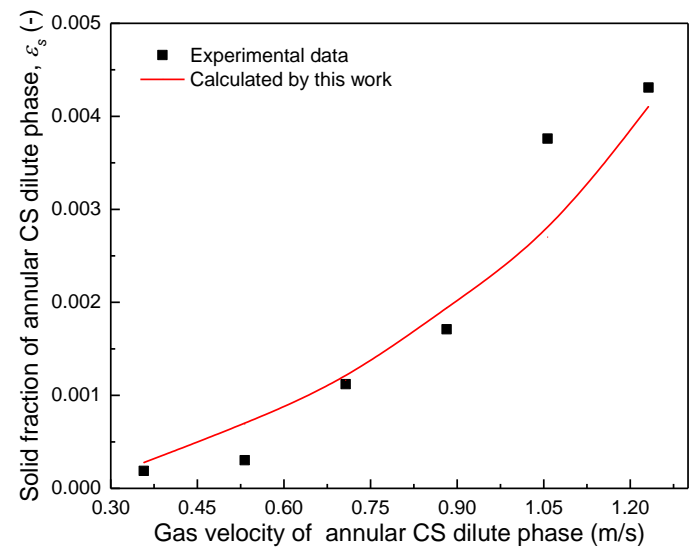

(b)

Figure 13 (a). Comparison between the typical experimental data and the calculated results by Ouyang and Potter's correlation; (b). Comparison between the typical experimental data and the calculated results by modified correlation

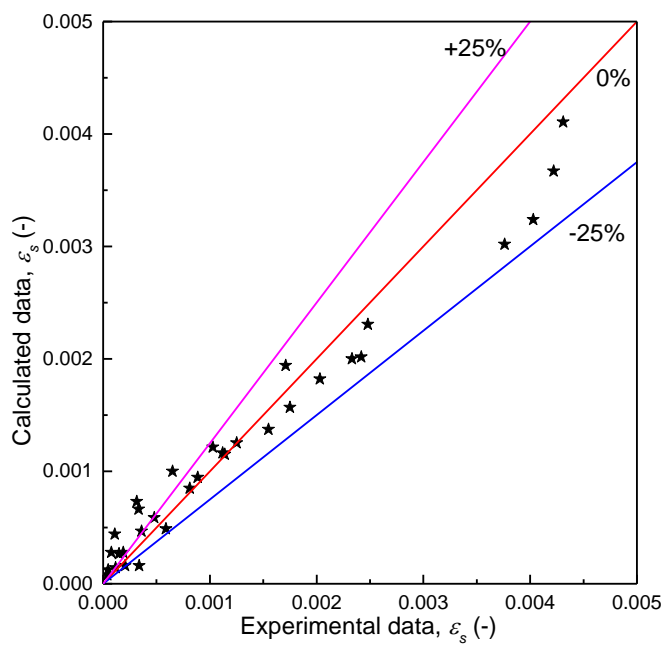

Figure 14. Comparison between the calculated results and the experimental data

\section{Conclusion}

A circulating turbulent fluidized bed (CTFB) consisting of a turbulent bed connected with a riser and an annular CS is proposed to be used as a fuel reactor in chemical looping combustion. A 1.5 $\mathrm{MW}_{\text {th }}$ cold flow model was designed, constructed and tested to investigate its hydrodynamics. Three kinds of quartz sand with different 
particle sizes $\left(\mathrm{d}_{50}=122 \mu \mathrm{m}, 249 \mu \mathrm{m}\right.$, and $\left.392 \mu \mathrm{m}\right)$ were used as bed materials. The cold model system achieved a continuous operation with reasonable pressure balance. Transition velocities from bubbling to turbulent fluidization with $\mathrm{d}_{50}=122 \mu \mathrm{m}, 249 \mu \mathrm{m}$, and $392 \mu \mathrm{m}$ were measured to be $0.78 \mathrm{~m} / \mathrm{s}, 0.95 \mathrm{~m} / \mathrm{s}$ and $1.06 \mathrm{~m} / \mathrm{s}$ respectively, indicating the transition velocity increased with increasing particle size. With the increase of gas velocity, the solid fraction in the dense phase of the turbulent fluidized bed with different particle sizes had a similar change trend, which was almost unchanged at first, then gradually decreased, and finally decreased rapidly. The correlation proposed by King was most applicable to predict the solid fraction of dense phase at different gas velocity. By comparing the effects of gas velocity and static bed height on the solid circulation rate, the solid circulation rate was more easily affected by gas velocity. A correlation proposed by Ouyang and Potter was modified to predict accurately the typical experimental results, and the relative errors were within $\pm 25 \%$ under various conditions.

\section{Acknowledgments}

This research is funded from National Key Research and Development Plan of China (No 2017YFE0112500) and European Union's Horizon 2020 Research and Innovation Program (No 764697). 


\section{Nomenclature}

Ar

AR

CLC

CS

CTFB

$\mathrm{d}_{50}$

$d_{p}$

$d_{p i \%}$

$D_{t}$

$F r_{D}$

$F r_{t}$

FR

$g$

$G_{s}$

$G_{s}^{*}$

$H$

$\Delta H_{i-j}$

$H_{\text {pipe }}$

$H_{\mathrm{s}}$

LS
Archimedes number, -

Air reactor

Chemical looping combustion

Carbon striper

Circulating turbulent fluidized bed

Median particle diameter, $\mu \mathrm{m}$

Particle diameter, $\mathrm{m}$

Particle diameter at $i \%$ in the cumulative distribution, $\mathrm{m}$

Bed diameter, $\mathrm{m}$

Froude number based on bed diameter, -;

Particle Froude number, -

Fuel reactor

Gravity acceleration, $\mathrm{m} / \mathrm{s}^{2}$

Solid circulation rate, $\mathrm{kg} /\left(\mathrm{m}^{2} \cdot \mathrm{s}\right)$

Saturation carrying capacity, $\mathrm{kg} /\left(\mathrm{m}^{2} \cdot \mathrm{s}\right)$

Expanded bed height, $\mathrm{m}$

Height from port $i$ to port $j, \mathrm{~m}$

Accumulative height of quartz sand in the cyclone dipleg, $\mathrm{m}$

Static bed height, $\mathrm{m}$

Loop seal 
$N$

$P_{\text {ave }}$

$P_{i}$

PSD

$\Delta P_{i-j}$

$R e_{c}$

$S_{C S}$

$S_{\text {pipe }}$

$t_{\text {pipe }}$

TFB

$u_{\mathrm{FR}}$

$u_{g}$

$u_{s}$

$u_{t}$

$U_{\mathrm{c}}$

$\rho_{b}$

$\rho_{g}$

$\rho_{p}$

$\varepsilon_{s}$

$\varepsilon_{s d}$

$\sigma$
Number of pressure drops, -

Average pressure drop, $\mathrm{kPa}$

Pressure drop at number $i, \mathrm{kPa}$

Particle size distributions

Pressure drop from port $i$ to port $j, \mathrm{~Pa}$

Reynolds number based on $R e_{c}=d_{p} U_{c} \rho_{g} / \mu_{g},-$

Sectional area of the annular CS, $\mathrm{m}^{2}$

Sectional area of the cyclone dipleg, $\mathrm{m}^{2}$

Elapsed time of quartz sand accumulation in the cyclone

dipleg, s

Turbulent fluidized bed

Gas velocity, $\mathrm{m} / \mathrm{s}$

Fluidizing gas velocity, $\mathrm{m} / \mathrm{s}$

Solid velocity, $\mathrm{m} / \mathrm{s}$

Terminal velocity, $\mathrm{m} / \mathrm{s}$

Transition velocity, $\mathrm{m} / \mathrm{s}$

Bulk density, $\mathrm{kg} / \mathrm{m}^{3}$

Density of fluidizing gas, $\mathrm{kg} / \mathrm{m}^{3}$

Particle density, $\mathrm{kg} / \mathrm{m}^{3}$

Solid fraction, -

Solid fraction of dense phase, -

Standard deviation of pressure fluctuation, $\mathrm{kPa}$ 
$\sigma_{p}$

$\mu_{g}$

$\varphi$
Standard deviation of particle size distribution, $\mathrm{m}$

Gas viscosity, $\mathrm{kg} /(\mathrm{m} \cdot \mathrm{s})$

Slip factor, - 


\section{References}

1. Gauthier, T.; Yazdanpanah, M.; Forret, A.; Amblard, B.; Lambert, A.; Bertholin, S., CLC, a promising concept with challenging development issues. Powder Technol. 2017, 316, 3-17.

2. Alghamdi, Y.; Peng, Z.; Zanganeh, J.; Moghtaderi, B.; Doroodchi, E., Hydrodynamics similarities in cold flow model of chemical looping combustors: An experimental study. Powder Technol. 2019, 343, 542-550.

3. Richter, H. J.; Knoche, K. F., Reversibility of combustion processes. Acs Symposium Series 1983, 235, 71-85.

4. Berguerand, N.; Lyngfelt, A., Design and operation of a $10 \mathrm{~kW}(\mathrm{th})$ chemical-looping combustor for solid fuels - Testing with South African coal. Fuel 2008, 87, (12), 2713-2726.

5. Stroehle, J.; Orth, M.; Epple, B., Design and operation of a $1 \mathrm{MW}_{\text {th }}$ chemical looping plant. Appl. Energy 2014, 113, 1490-1495.

6. Linderholm, C.; Schmitz, M.; Knutsson, P.; Lyngfelt, A., Chemical-looping combustion in a $100-\mathrm{kW}$ unit using a mixture of ilmenite and manganese ore as oxygen carrier. Fuel 2016, 166, 533-542.

7. Ohlemueller, P.; Stroehle, J.; Epple, B., Chemical looping combustion of hard coal and torrefied biomass in a $1 \mathrm{MW}_{\text {th }}$ pilot plant. Int. J. Greenhouse Gas Control 2017, 65, 149-159.

8. Abdulally, I.; Andrus, H. E.; Edberg, C.; Chiu, J.; Thibeault, P.; Lani, B., ALSTOMs chemical looping combustion prototype for $\mathrm{CO}_{2}$ capture from existing pulverized coal fired power plants. In: NETL $\mathrm{CO}_{2}$ capture technology meeting, 2012.

9. Bayham, S.; McGiveron, O.; Tong, A.; Chung, E.; Kathe, M.; Wang, D.; Zeng, L.; Fan, L.-S., Parametric and dynamic studies of an iron-based $25-\mathrm{kW}($ th) coal direct chemical looping unit using sub-bituminous coal. Appl. Energy 2015, 145, 354-363.

10. Adanez, J.; Abad, A.; Mendiara, T.; Gayan, P.; de Diego, L. F.; Garcia-Labiano, F., Chemical looping combustion of solid fuels. Prog. Energy Combust. Sci. 2018, 65, 6-66.

11. Guio-Perez, D. C.; Proell, T.; Hofbauer, H., Influence of ring-type internals on the solids residence time distribution in the fuel reactor of a dual circulating fluidized bed system for chemical looping combustion. Chem. Eng. Res. Des. 2014, 92, (6), 1107-1118.

12. Lyngfelt, A.; Pallares, D.; Linderholm, C.; Ryden, M.; Mattisson, T. Distributor of volatile gases in the bottom part of a fluidized bed. Swedish Patent Application No. 1400085-5, 2014.

13. Markstrom, P.; Linderholm, C.; Lyngfelt, A., Operation of a $100 \mathrm{~kW}$ chemical-looping combustor with Mexican petroleum coke and Cerrejon coal. Appl. Energy 2014, 113, 1830-1835.

14. Stroehle, J.; Orth, M.; Epple, B., Chemical looping combustion of hard coal in a $1 \mathrm{MW}_{\text {th }}$ pilot plant using ilmenite as oxygen carrier. Appl. Energy 2015, 157, 288-294.

15. Perez-Vega, R.; Abad, A.; Garcia-Labiano, F.; Gayan, P.; de Diego, L. F.; Adanez, J., Coal combustion in a $50 \mathrm{~kW}$ (th) Chemical Looping Combustion unit: Seeking operating conditions to maximize $\mathrm{CO}_{2}$ capture and combustion efficiency. Int. J. Greenhouse Gas Control 2016, 50, 80-92.

16. Sun, H.; Cheng, M.; Chen, D.; Xu, L.; Li, Z.; Cai, N., Experimental Study of a Carbon Stripper in Solid Fuel Chemical Looping Combustion. Ind. Eng. Chem. Res. 2015, 54, (35), 8743-8753. 
17. Sun, H.; Cheng, M.; Li, Z.; Cai, N., Riser-Based Carbon Stripper for Coal-Fueled Chemical Looping Combustion. Ind. Eng. Chem. Res. 2016, 55, (8), 2381-2390.

18. Cheng, M.; Sun, H.; Li, Z.; Cai, N., Annular Carbon Stripper for Chemical-Looping Combustion of Coal. Ind. Eng. Chem. Res. 2017, 56, (6), 1580-1593.

19. Chen, H.; Cheng, M.; Liu, L.; Li, Y.; Li, Z.; Cai, N., Coal-fired chemical looping combustion coupled with a high-efficiency annular carbon stripper. Int. J. Greenhouse Gas Control 2020, 93.

20. Cheng, M.; Li, Y.; Li, Z.; Cai, N., An integrated fuel reactor coupled with an annular carbon stripper for coal-fired chemical looping combustion. Powder Technol. 2017, 320, 519-529.

21. Gauthier, T.; Hoteit, A.; Guillou, F.; Stainton, H. Chemical looping combustion method with a reaction zone including a gas-solid separation zone and plant using same. US9927118, 2018.

22. Lyngfelt, A.; Leckner, B., A $1000 \mathrm{MW}_{\text {th }}$ boiler for chemical-looping combustion of solid fuels - Discussion of design and costs. Appl. Energy 2015, 157, 475-487.

23. Adanez, J.; Abad, A.; Garcia-Labiano, F.; Gayan, P.; de Diego, L. F., Progress in chemical-looping combustion and reforming technologies. Prog. Energy Combust. Sci. 2012, 38, (2), 215-282.

24. Linderholm, C.; Abad, A.; Mattisson, T.; Lynyfelt, A., $160 \mathrm{~h}$ of chemical-looping combustion in a $10 \mathrm{~kW}$ reactor system with a NiO-based oxygen carrier. Int. J. Greenhouse Gas Control 2008, 2, (4), 520-530.

25. Kim, H. R.; Wang, D.; Zeng, L.; Bayham, S.; Tong, A.; Chung, E.; Kathe, M. V.; Luo, S.; McGiveron, O.; Wang, A.; Sun, Z.; Chen, D.; Fan, L.-S., Coal direct chemical looping combustion process: Design and operation of a 25-kW(th) sub-pilot unit. Fuel 2013, 108, 370-384.

26. Adanez, J.; Cuadrat, A.; Abad, A.; Gayan, P.; de Diego, L. F.; Garcia-Labiano, F., Ilmenite activation during consecutive redox cycles in chemical-looping combustion. Energy Fuels 2010, 24, (2), 1402-1413.

27. Darton, R. C.; Lanauze, R. D.; Davidson, J. F.; Harrison, D., Bubble-growth due to coalescence in fluidized-beds. Trans. Inst. Chem. Eng. 1977, 55, (4), 274-280.

28. Rim, G.; Lee, D., Bubbling to turbulent bed regime transition of ternary particles in a gas-solid fluidized bed. Powder Technol. 2016, 290, 45-52.

29. Bi, H. T.; Ellis, N.; Abba, I. A.; Grace, J. R., A state-of-the-art review of gas-solid turbulent fluidization. Chem. Eng. Sci. 2000, 55, (21), 4789-4825.

30. Yerushalmi, J.; Cankurt, N. T., Further-studies of the regimes of fluidization. Powder Technol. 1979, 24, (2), 187-205.

31. Jin, Y.; Yu, Z. Q.; Wang, Z. W.; Cai, P., A criterion for transition from bubbling to turbulent fuidization. In Fluidization V, Engineering Foundation, New York, 1986, pp. 289-296.

32. Lee, G. S.; Kim, S. D., Pressure-fluctuations in turbulent fluidized-beds. J. Chem. Eng. Jpn. 1988, 21, (5), 515-521.

33. Cai, P.; Chen, S. P.; Jin, Z. Q.; Wang, Z. W., Effect of operating temperature and pressure on the transition from bubbling to turbulent fluidization. J. Chem. Ind. Eng. 1989, 5, 122-132.

34. Horio, M., Hydrodynamics of circulating fuidization: Present status and research needs. In Circulating Fluidized Bed Technology III, Basu P.; Horio M.; Hasatani M. (Eds.), Pergamon, Oxford, 1991, pp. 3-14.

35. Nakajima, M.; Harada, M.; Yamazaki, R.; Jimbo, G., Bubble fraction and voidage in an emulsion phase in the transition to a turbulent fluidized bed. Kagaku Kogaku Ronbunshu 1990, 16, (2), 322-328. 
36. Dunham, G. E.; Mann, M. D.; Grewal, N. S., Dependence of transition to turbulent fluidization on static bed depth in a fluidized bed. In Preprints of the fourth international conference on circulating yuidized beds, Somerset, PA, 1993.

37. Bi, H. T.; Grace, J. R., Effect of measurement method on the velocities used to demarcate the onset of turbulent fluidization. Chem. Eng. J. 1995, 57, (3), 261-271.

38. Yazdanpanah, M.; Forret, A.; Gauthier, T., Impact of size and temperature on the hydrodynamics of chemical looping combustion. Appl. Energy 2015, 157, 416-421.

39. Cai, P. The transition of flow regime in dense phase gas-solid fluidized bed. Tsinghua University, Beijing, China, 1989.

40. Chehbouni, A.; Chaouki, J.; Guy, C.; Klvana, D., ffets de différents paramètres sur les vitesses du transition de la fluidisation en régime turbulent. Can. J. Chem. Eng. 1995, 73, 41-50.

41. King, D. F., Estimation of dense bed voidage in fast and slow fluidized beds of FCC catalyst. In Fluidization VI, Engineering Foundation, Grace, J. R.; Schemilt, L. W.; Bergougnou, M. A. (Eds.), New York, 1989, pp. 1-8.

42. Monazam, E. R.; Shadle, L. J., Analysis of the Acceleration Region in a Circulating Fluidized Bed Riser Operating above Fast Fluidization Velocities. Ind. Eng. Chem. Res. 2008, 47, (21), 8423-8429.

43. Miao, Q.; Zhu, J.; Barghl, C.; Wanfi, C.; Yin, X. L.; Wu, C. Z., Axial and radial solids holdup modeling of circulating fluidized bed risers. In Proceedings of the 20th International Conference on Fluidized Bed Combustion, 2010; 335-340.

44. Wong, R.; Pugsley, T.; Berruti, F., Modelling the axial voidage profile and flow structure in risers of circulating fluidized beds. Chem. Eng. Sci. 1992, 47, (9-11), 2301-2306.

45. Kunii, D.; Levenspiel, O., Flow modeling of fast fluidized bed. In Circulating Fluidized Bed Technology III, Basu P.; Hasatani M.; Horio M. (Eds.), Pergamon, Oxford, UK, 1991, pp. 91-98.

46. Pugsley, T. S.; Patience, G. S.; Berruti, F.; Chaouki, J., Modelling the oxidation of n-butane to maleic anhydride in a circulating fluidized bed reactor. Ind. Eng. Chem. Res. 1992, 31, (12), 2652-2660.

47. Patience, G. S.; Chaouki, J.; Berruti, F.; Wong, R., Scaling considerations for circulating fluidized-bed risers. Powder Technol. 1992, 72, (1), 31-37.

48. Ouyang, S.; Potter, O. E., Consistency of circulating fluidized bed experimental data. Ind. Eng. Chem. Res. 1993, 32, (6), 1041-1045.

49. Bai, D.; Kato, K., Quantitative estimation of solids holdups at dense and dilute regions of circulating fluidized beds. Powder Technol. 1999, 101, (3), 183-190.

50. Issangya, A. S.; Grace, J. R.; Zhu, J. X., Bottom and exit region solids hold-ups in circulating fluidized bed risers. In Circulating Fluidized Bed Technology VIII, Cen K. (Ed.), International Academic Publishers, Hangzhou, 2005, pp. 209-215.

51. Huang, W. X.; Yan, A. J.; Zhu, J. J., Axial solids distribution and flow development in the risers of circulating fluidized beds with different heights. J. Chin. Inst. Chem. Eng. 2005, 36, (1), $17-24$.

52. Qi, X.-B.; Zhu, J.; Huang, W.-X., A new correlation for predicting solids concentration in the fully developed zone of circulating fluidized bed risers. Powder Technol. 2008, 188, (1), 64-72.

53. Xu, J.; Lu, X.; Zhang, W.; Chen, J.; Wang, Q.; Chen, Y.; Guo, Q., Effects of superficial gas velocity and static bed height on gas-solid flow characteristics in a 60-meter-high transparent CFB riser. Chem. Eng. J. 2018, 334, 545-557. 